\section{PENGARUH KEPEMIMPINAN TRANSFORMASIONAL TERHADAP ORGANIZATIONAL CITIZENSHIP BEHAVIOR DENGAN IKLIM ORGANISASI SEBAGAI VARIABEL INTERVENING (STUDI PADA KANTOR DUKCAPIL KOTA MATARAM)}

\author{
Khaerul Amri ${ }^{1}$ \\ Zainal Abidin ${ }^{2}$ \\ Siti Nurmayanti ${ }^{3}$ \\ arirozhu@yahoo.com
}

\begin{abstract}
This study aims to analyze the influence of Transformational Leadership on $O C B$, to analyze the influence of Transformational Leadership on Organizational Climate, to analyze the influence of Organizational Climate on OCB, to analyze the Climate of Transformational Leadership Mediation Organization against OCB. This research was conducted at Population and Civil Registration District Agency Of Mataram with 45 people as a sample using saturated sampling technique that is sample determination technique when all member of population used as sample. The type of this research was associative causal research and data collection tool was Analysis PLS-SEM. The results of the data analysis shows that, transformational leadership has a positive and significant effect on $O C B$. The Climate Organization has a positive and significant impact on OCB. Transformational leadership has a positive and significant influence on the Climate of the Organization. Transformational leadership has a positive and significant impact on OCB through the Climate of the Organization.
\end{abstract}

Keywords: Transformational Leadership, Organizational Climate and OCB.

\section{PENDAHULUAN}

Menurut Robbins dan Judge (2009:120) organisasi yang sukses adalah organisasi yang membutuhkan karyawan yang mampu bertindak melebihi tugas pekerjaan umum mereka, atau memberikan kinerja yang melampaui perkiraan dan fakta menunjukkan bahwa organisasi yang mempunyai karyawan yang memiliki Organizational Citizenship Behavior (OCB) yang baik, akan memiliki kinerja yang lebih baik daripada organisasi lain. Organizational citizenship behavior (OCB) dipengaruhi banyak faktor. Salah satu faktor yang dapat membentuk (OCB) adalah gaya kepemimpinan. Shahzad et.al (dalam Titisari, 2014: 44) menemukan bahwa gaya kepemimpinan berpengaruh signifikan terhadap Organizational Citizenship Behavior (OCB). Gaya kepemimpinan yang dimaksud adalah kepemimpinan transformasional. Kepemimpinan transformasional adalah upaya menggerakan semua sumber daya kekuatan organisasi, menciptakan perbedaan dan perubahan besar dalam kelompok dan organisasi, membesarkan kolega-subordinate untuk mencapai kesadaran yang lebih besar atas perannya dalam organisasi (Shamir dalam Lako, 2004:72). Faktor lain yang dapat mempengaruhi OCB adalah iklim organisasi (Vannecia, 2013). Organ (2006:161) juga menegaskan bahwa terdapat bukti kuat yang mengemukakan bahwa iklim organisasi merupakan suatu kondisi awal yang utama yang memicu munculnya perilaku OCB. Di dalam iklim organisasi yang positif, karyawan merasa lebih ingin melakukan pekerjaannya melebihi apa yang telah disyaratkan dalam uraian

\footnotetext{
${ }^{1}$ Kantor Kelurahan Bintaro

2 Program Magister Manajemen Universitas Mataram

3 Program Magister Manajemen Universitas Mataram
} 
pekerjaan, dan akan selalu mendukung tujuan organisasi jika mereka diperlakukan oleh para atasan dengan sportif dan dengan penuh kesadaran serta percaya bahwa mereka diperlakukan secara adil oleh organisasinya (Sloat, 1999:184).

Beberapa hasil penelitian terdahulu yang dapat dijadikan riset gap dalam penelitian ini, yaitu Helmiatin, (2012), Mahrita, et.al (2015), Arifiani, et.al (2016), membuktikan bahwa kepemimpinan transformasional tidak berpengaruh signifikan terhadap perilaku ekstra peran (OCB). Namun hasil penelitian ini berbeda dengan hasil penelitian yang dilakukan oleh Zulbaldi, et.al (2014), Rahmi (2014), Suryanatha, et.al (2014), Purpa, et.al (2015), Adipurwa, et.al (2015), Gunawan (2016), Putra, et.al (2016), dan Muflikhun (2016), menyatakan bahwa kepemimpinan transformasional berpengaruh signifikan terhadap perilaku ekstra peran (OCB). Sedangkan penelitian yang dilakukan oleh Ngadiman, et.al (2013), membuktikan bahwa kepemimpinan transformasional dan iklim organisasi tidak berpengaruh signifikan terhadap perilaku ekstra peran (OCB). Berbeda dengan hasil penelitian yang dilakukan oleh Amelia (2014), bahwa terdapat hubungan yang positif dan signifikan baik secara simultan maupun parsial antara kepemimpinan Transformasional dan iklim organisasi terhadap perilaku ekstra peran (OCB). Hasil penelitian ini didukung oleh penelitian Sari, et.al (2013), membuktikan bahwa terdapat hubungan antara kepemimpinan transformasional dengan perilaku ekstra peran (OCB), dimana ditemukan bahwa semakin efektif kepemimpinan transformasional maka akan semakin tinggi perilaku ekstra peran $(\mathrm{OCB})$.

Gambaran umum tentang perilaku ekstra peran (OCB) pegawai negeri sipil di lingkungan Dinas DUKCAPIL Kota Mataram, dimana perilaku pegawai yang memperlihatkan perilaku OCB terhadap organisasinya hanya sebagian kecil dari jumlah pegawai yang ada. Permasalahan inipun sudah ada saat adanya pengawasan internal organisasi Dinas DUKCAPIL. Hal tersebut merupakan indikasi bahwa beberapa pegawai tidak secara sukarela membantu organisasi dalam tujuan bersama, dimana terlihat pegawai hanya mencari perhatian pada pimpinan saat bekerja.

Berdasarkan hasil survei awal, beberapa pegawai mengeluh rendahnya frekwensi pembinaan dari pimpinan, kurangnya memperhatikan faktor kepuasan kerja pegawai oleh pimpinan serta kurangnya pengakuan atas status para pegawai secara tepat dan professional dari sikap pimpinan. Hal ini mengindikasikan kurangnya sikap pimpinan dalam mempengaruhi perilaku OCB pegawai pada lingkungan Dinas DUKCAPIL Kota Mataram. Jika suasana lingkungan kerja yang kurang mendukung, dapat berakibat rendahnya perilaku OCB pada pegawai. Pimpinan dalam penelitian ini adalah Kepala Dinas DUKCAPIL yang langsung berperan untuk mempengaruhi perilaku OCB pegawai.

Wawancara awal dilakukan oleh peneliti, terlihat hubungan antara pimpinan dan pegawai belum adanya saling mendukung satu sama lain, rendahnya manajemen partisipatif baik dari pegawai maupun pimpinan dalam organisasi, serta kurangnya pelatihan dan pengembangan pegawai dilingkungan Dinas Dukcapil Kota Mataram. Berdasarkan pada pengamatan sementara, peneliti melihat beberapa ciri yang didindikasi merupakan gaya kepemimpinan transformasional yang diterapkan oleh kepala Dinas Dukcapil Kota Mataram di lingkungan kerja kantor Dinas Dukcapil Kota Mataram. Gaya kepemimpinan Transformasional diterapkan oleh pimpinan terutama dalam menjelaskan visi dan misi, memunculkan rasa bangga serta memberikan kepercayaan kepada bawahan dalam tugas. Dalam meningkatkan kecerdasan para pegawai, pimpinan menunjukkan perilaku memberikan kepercayaan diri pada pegawai untuk meningkatkan kreativitas dan inovasi mereka serta meningkatkan rasionalitas dan pemecahan masalah secara cermat serta memberikan saran kepada pegawai dalam perbaikan tugas yang dikerjakan. 


\section{$J M M$

Berdasarkan teori, penelitian terhadahulu dan fenomena di atas maka penulis tertarik untuk menganalisis pengaruh Kepemimpinan Transformasional terhadap OCB, menganalisis pengaruh Kepemimpinan Transformasional terhadap Iklim Organisasi, menganalisis pengaruh Iklim Organisasi terhadap OCB dan menganalisis Iklim Organisasi dalam memediasi Kepemimpinan Transformasional terhadap OCB.

\section{METODE PENELITIAN}

\subsection{Jenis Penelitian}

Jenis penelitian yang digunakan dalam penelitian ini adalah penelitian Asosiatif kausal (Sebab Akibat). Menurut Sugiyono (2011:36), rumusan masalah asosiatif adalah suatu rumusan masalah penelitian yang bersifat menanyakan hubungan antara dua variabel atau lebih. Terdapat tiga bentuk hubungan yitu: hubungan simetris, hubungan kausal (sebab akibat) dan interaktif/ resiprocal/timbal balik. Hubungan kausal adalah hubungan yang bersifat sebab akibat.

\subsection{Populasi dan Sampel}

Jumlah tenaga kerja (Pegawai) di Dinas Kependudukan dan Pencatatan Sipil Kota Mataram sampai dengan akhir Tahun 2015 berjumlah 89 orang terdiri dari Pegawai Negeri Sipil 45 orang, Pegawai Tidak Tetap berjumlah 43 orang adalah tenaga kontrak. (sumber: LAKIP dukcapil Kota Mataram 2014-2015).

Sampel adalah bagian dari jumlah dan karakteristik yang dimiliki oleh populasi tersebut (Sugiyono, 2014). Teknik pengambilan sampel menggunakan sampling jenuh yaitu teknik penentuan sampel bila semua anggota populasi digunakan sebagai sampel. Dalam penelitian ini peneliti menggunakan semua pegawai negeri sipil pada DUKCAPIl Kota Mataram yang akan menjadi sebagai sampel.

\subsection{Metode Analisis}

Analisis data dan pengujian hipotesis penelitian ini dilakukan dengan pendekatan Partial Least Square (PLS) dengan menggunakan software SmartPLS versi 3.0. PLS adalah model persamaan struktural (SEM) yang berbasis komponen atau varian (variance). Menurut Ghozali dan Latan (2015:7) analisis PLS-SEM biasanya terdiri dari dua sub mdel yaitu model pengukuran (measurement model) atau sering disebut auter model. Model pengukuran menunjukan bagaimana variabel manifest atau observed variabel merepresentatif variabel laten untuk diukur. Sedangkan model structural menunjukkan kekuatan estimasi antar variabel laten atau konstruk.

\section{HASIL PENELITIAN}

\subsection{Karakristik Responden Berdasarkan Umur, Jenis Kelamin, Tingkat} Pendidikan, dan Masa Kerja.

Tabel 3.1 Karakteristik Responden Berdasarkan jenis kelamin, pendidikan terakhir, usia dan lama kerja

\begin{tabular}{|c|c|c|c|}
\hline \multicolumn{2}{|c|}{ Profil Responden } & Jumlah (orang) & Persentase (\%) \\
\hline Jenis Kelamin & Laki-laki & 24 & 53 \\
\cline { 2 - 4 } & Perempuan & 21 & 47 \\
\hline \multirow{3}{*}{$\begin{array}{c}\text { Pendidikan } \\
\text { terakhir }\end{array}$} & SMA & 15 & 33 \\
\cline { 2 - 4 } & D III & 0 & 0 \\
\cline { 2 - 4 } & S1 & 28 & 62 \\
\cline { 2 - 4 } & S2 & 2 & 4 \\
\hline
\end{tabular}




\section{$J M M$

\begin{tabular}{|c|c|c|c|}
\hline \multirow{4}{*}{ Usia (Tahun) } & $<21$ & 0 & 0 \\
\cline { 2 - 4 } & $21-30$ & 11 & 24 \\
\cline { 2 - 4 } & $31-40$ & 11 & 24 \\
\hline \multirow{3}{*}{$\begin{array}{c}\text { Lama Kerja } \\
\text { (tahun) }\end{array}$} & $>40$ & 23 & 51 \\
\cline { 2 - 4 } & $<5$ tahun & 0 & 0 \\
\cline { 2 - 4 } & $6-15$ tahun & 30 & 67 \\
\hline \multicolumn{2}{|c|}{ Jumlah Sampel } & 15 & 33 \\
\hline
\end{tabular}

Sumber : Data primer diolah, 2017 (Lampiran 2)

Berdasarkan Tabel 3.1 dapat dilihat bahwa responden didominasi oleh responden berjenis kelamin laki-laki dengan jumlah 24 orang dari 45 responden atau sekitar $53 \%$. Sedangkan responden yang berjenis kelamin perempuan berjumlah 21 orang responden atau sekitar $47 \%$ dari jumlah keseluruhan responden. Pada penelitian ini, lebih dominan responden laki-laki dibandingkan dengan responden perempuan.

Karakteristik responden dengan jenis tingkat pendidikan terakhir dalam penelitian ini terlihat sebagain besar memiliki tingkat pendidikan sarjana tingkat satu atau strata satu sebanyak 28 orang atau $62 \%$. Pada sarjana tingkat dua atau strata dua sebanyak 2 orang atau $4 \%$. Sedangkan tingkat pendidikan pada sekolah menengah atas (SMA) sebanyak 15 orang atau $33 \%$. Jadi dalam penelitian ini terlihat tingkat pendidikan strata satu yang mendominasi tingkat pendidikan pegawai pada DUKCAPIL Kota Mataram.

Pada Tabel 3.1 tersebut dapat dilihat bahwa responden terbanyak adalah pada kelompok umur $>40$ tahun yaitu 23 orang pegawai atau 51\%. Sedangkan kelompok umur yang paling sedikit adalah kelompok umur 21- 40 tahun sebanyak 11 orang pegawai atau $24 \%$. Hal ini terlihat bahwa umur responden pegawai negeri sipil pada kantor DUKCAPIL Kota Mataram sebagaian besar berusia berkisar usia $>40$ tahun.

Berdasarkan tabel 6.1 tersebut dapat dilihat bahwa responden terbanyak adalah dengan masa kerja 6-15 tahun sebanyak 30 orang pegawai atau $67 \%$. Hal ini menunjukkan bahwa masa kerja pegawai negeri sipil pada kantor DUKCAPIL Kota Mataram sudah dikategorikan cukup lama, dimana terlihat para pegawai menunjukkan adanya rasa tanggungjawab dalam menjalankan tugas sebagai pegawai negeri sipil yang artinya masa kerja yang lama akan cenderung membuat para pegawai lebih merasa betah dalam suatu organisasi dikarenakan telah beradaptasi secara emosional dengan lingkungannya yang cukup lama.

\subsection{Analisis Partial Last Square (PLS)}

3.2.1. Evaluasi Model Pengukuran (Measurement Model/Outer Model)

\subsubsection{Convergent Validity}

1) Variabel Kepemimpinan Transformasional $(X)$

Suatu indikator dinyatakan valid jika mempunyai loading factor di atas 0,5 terhadap konstruk yang dituju. Output SmartPLS untuk loading factor konstruk pada variabel kepemimpinan transformasional terdiri dari 11 indikator yaitu : Pimpinan menyampaikan visi dan misi, Pimpinan membanggakan, Kepercayaan, Membangkitkan semangat, Mengispirasi, Merangsang Kreativitas dan Inovasi, Menghargai ide-ide, Mengarahkan, Memberikan perhatian, Menghargai perbedaan, Melatih dan memberi penghargaan. Dari output path diagram pada hasil output dapat dilihat indikator yang 


\section{$J M M$

memiliki nilai loading factor $>0,50$. Oleh karena itu, indikator-indikator kepemimpinan transformasional tersebut selanjutnya dapat dianalisis dalam model penelitian.

2) Variabel Iklim Organisasi (Z)

Suatu indikator dinyatakan valid jika mempunyai loading factor di atas 0,5 terhadap konstruk yang dituju. Output SmartPLS untuk loading factor konstruk pada variabel iklim organisasi terdiri dari 6 indikator yaitu : Hubungan antar personal, Manajemen partisipatif, Formalisasi dan standarisasi, Pelatihan dan pengembangan, Reward, Obyektivitas dan rasionalitas. Dari output path diagram pada hasil output dapat dilihat indikator yang memiliki nilai loading factor $>0,50$. Oleh karena itu, indikator-indikator iklim organisasi tersebut selanjutnya dapat dianalisis dalam model penelitian.

3) Variabel Organizational Citizenship Behavior (Y)

Suatu indikator dinyatakan valid jika mempunyai loading factor di atas 0,5 terhadap konstruk yang dituju. Output SmartPLS untuk loading factor konstruk pada variabel organizational citizenship behavior terdiri dari 15 indikator yaitu : Membantu rekan kerja yang beban kerjanya berlebih, Menggantikan peran atau pekerjaan rekan kerja yang berhalangan hadir, Rela membantu rekan kerja yang memiliki masalah dengan pekerjaan, Membantu rekan kerja yang lain agar lebih produktif, Mencoba untuk tidak membuat masalah dengan rekan kerja, Mencoba menghindari terjadinya perselisihan antar rekan kerja, Mempertimbangkan dampak terhadap rekan kerja dari setiap tindakan yang dilakukan, Berkonsultasi terlebih dahulu dengan rekan kerja yang mungkin akan terpengaruh dengan tindakan yang akan dilakukan, Tidak menghabiskan waktu untuk mengeluh atas permasalahan yang sepele, Tidak membesar-besarkan permasalahan yang terjadi dalam organisasi, Menerima setiap kebijakan dan prosedur yang ditetapkan oleh organisasi, Menyelesaikan tugas sebelum waktunya, Selalu berusaha melakukan lebih dari apa yang seharusnya dilakukan, Secara sukarela melakukan sesuatu yang bermanfaat bagi organisasi disamping tugas utama, Peduli terhadap perkembangan dan perubahan yang terjadi dalam organisasi, Turut serta dalam berbagai kegiatan yang diselenggarakan oleh organisasi, Mengambil inisiatif untuk memberikan rekomendasi atau saran inovatif untuk meningkatkan kualitas organisasi secara keseluruhan. Hasil indikator yang memiliki nilai factor loading $>$ 0,50 dalam model penelitian ini diperoleh hasil sesuai Gambar 1. yang merupakan output path diagram pada SmartPLS 3.0. sebagai berikut:

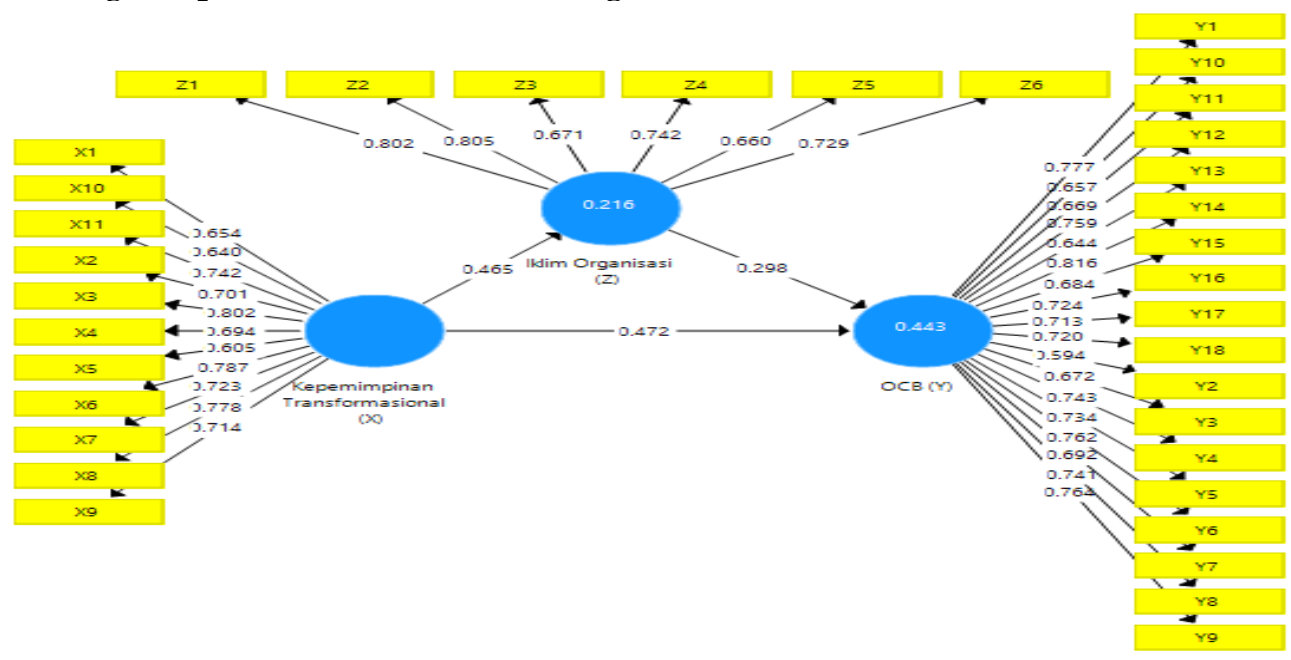

Gambar 1. Tampilan Hasil PLS Algorithm 
Dengan demikian, metode lain untuk melihat discriminant validity adalah dengan melihat nilai average variance extracted (AVE). Nilai yang disarankan adalah di atas 0,5. Berikut adalah nilai AVE dalam penelitian ini:

\subsubsection{Discriminant Validity}

Tabel 3.2. Discriminant Validity

\begin{tabular}{|c|l|c|c|c|}
\hline No & \multicolumn{1}{|c|}{ Variabel } & IO (Z) & KT (X) & OCB (Y) \\
\hline $\mathbf{1 .}$ & Iklim Organisasi (Z) & 0,737 & & \\
\hline $\mathbf{2 .}$ & $\begin{array}{l}\text { Kepemimpinan } \\
\text { Transformasional (X) }\end{array}$ & 0,465 & 0,715 & \\
\hline $\mathbf{3 .}$ & OCB (Y) & 0,518 & 0,611 & 0,717 \\
\hline
\end{tabular}

Sumber : Data primer diolah, 2017

Tabel 3.4. Average Variance Extracted (AVE)

\begin{tabular}{|c|l|c|}
\hline No & \multicolumn{1}{|c|}{ Variabel } & AVE \\
\hline $\mathbf{1 .}$ & Iklim Organisasi (Z) & 0,543 \\
\hline $\mathbf{2 .}$ & Kepemimpinan Transformasional (X) & 0,512 \\
\hline $\mathbf{3 .}$ & OCB (Y) & 0,514 \\
\hline
\end{tabular}

Sumber : Data primer diolah, 2017

Tabel di atas memberikan nilai AVE di atas 0,5 untuk semua konstruk yang terdapat pada model penelitian. Hasil ini dapat dilakukan analisis selanjutnya.

\subsubsection{Composite Reliability}

Uji reliabilitas dilakukan dengan melihat nilai composite reliability dan cronbachs alpha dari blok indikator yang mengukur konstruk. Hasil composite reliability akan menunjukkan nilai yang memuaskan jika di atas 0,7. Sedangkan nilai cronbachs alpha yang disarankan adalah berkisar 0,6. Berikut adalah nilai composite reliability dan cronbachs alpha pada output:

Tabel 3.5. Composite Reliability dan Cronbachs Alpha

\begin{tabular}{|c|l|c|c|}
\hline No & \multicolumn{1}{|c|}{ Variabel } & $\begin{array}{l}\text { Composite } \\
\text { Reliability }\end{array}$ & Cronbachs Alpha \\
\hline $\mathbf{1 .}$ & Iklim Organisasi (Z) & 0,876 & 0,834 \\
\hline $\mathbf{2 .}$ & $\begin{array}{l}\text { Kepemimpinan } \\
\text { Transformasional (X) }\end{array}$ & 0,920 & 0,904 \\
\hline 3. & OCB (Y) & 0,950 & 0,944 \\
\hline
\end{tabular}

Sumber : Data primer diolah, 2017 (Lampiran 6)

Tabel di atas menunjukkan bahwa nilai composite reliability untuk semua konstruk adalah di atas 0,7 yang menunjukkan bahwa semua konstruk pada model yang diestimasi memenuhi kriteria discriminant validity. 


\section{$J M M$

\subsubsection{Evaluasi Model Struktural (Structural Model/Inner Model)}

Setelah model yang diestimasi memenuhi kriteria Outer Model, berikutnya dilakukan pengujian model structural (Inner model). Berikut adalah nilai R-Square pada konstruk:

\subsubsection{Koefisien Determinasi $\left(\mathbf{R}^{2}\right)$}

Nilai R Square sebenarnya menggambarkan seberapa besar kemampuan variabel bebas dalam menjelaskan variabel terikat. Berikut ini dapat dilihat pada tebel :

\begin{tabular}{|c|c|c|}
\hline No & Variahot & \\
\hline & Valdaver & is square \\
\hline 1. & $\begin{array}{l}\text { Kepemimpinan } \\
\text { Transformasional }(X)\end{array}$ & \\
\hline 2. & Iklim Organisasi (Z) & 0,216 \\
\hline 3. & OCB (Y) & 0,443 \\
\hline
\end{tabular}

Konstruk kepemimpinan transformasional tidak mempunyai R Square karena tidak diprediksi oleh konstruk yang lain. Sedangkan Iklim organisasi mempunyai R Square sebesar 0,216 berarti Kepemimpinan Transformasional mampu menjelaskan variasi dari Iklim Organisasi sebesar 21,6\% di mana sisanya yaitu sebesar 78,4\% dijelaskan oleh faktor lain. Demikian juga, OCB mempunyai $\mathrm{R}$ Square sebesar 0,443 berarti Kepemimpinan Transformasional mampu menjelaskan varians OCB sebesar 44,3\% dimana selebihnya yaitu sebesar $55,7 \%$ dijelaskan oleh faktor lain.

\subsubsection{Estimasi Koefisien Jalur}

\section{Gambar 2. PLS Boothstrapping}

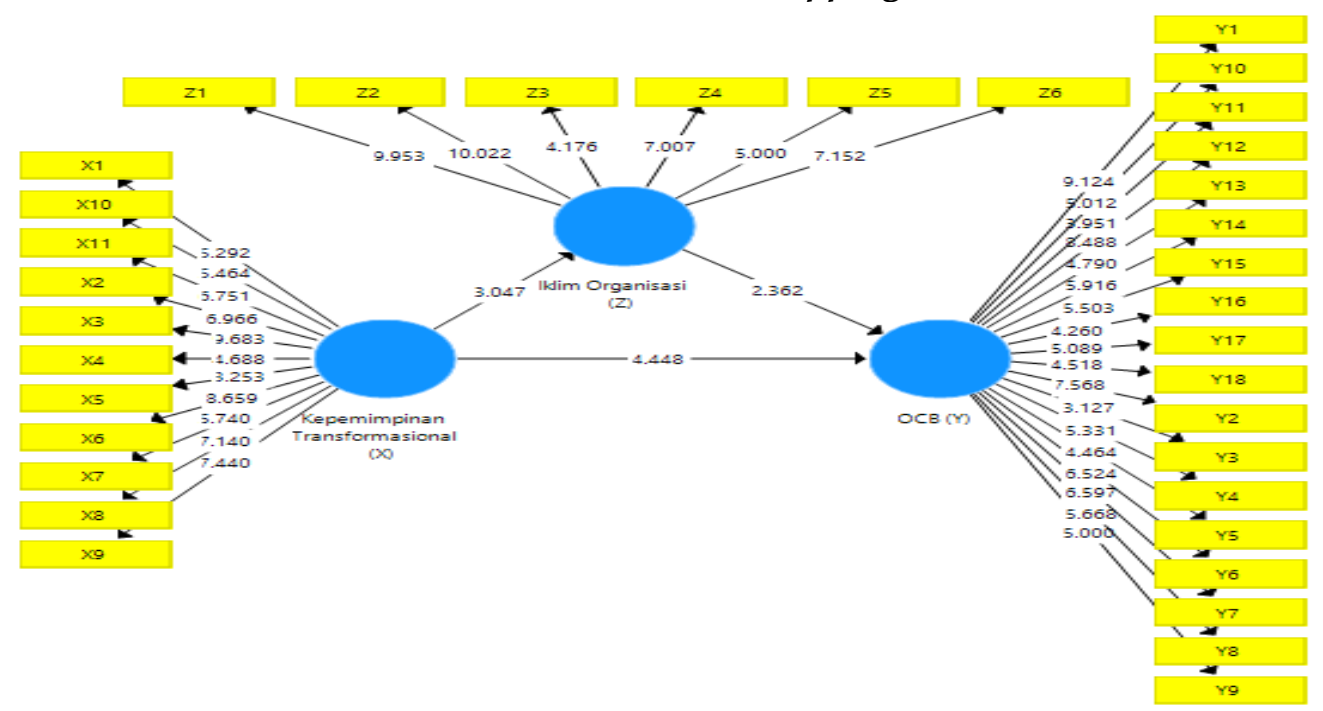

Untuk menilai signifikansi model prediksi dalam pengujian model struktural, dapat dilihat dari nilai $t$-statistic antara variabel independen ke variabel dependen dalam tabel Path Coefficient pada output SmartPLS dibawah ini: 


\section{$J M M$

Tabel 4.17. Hasil Koefisien Jalur

\begin{tabular}{|c|c|c|c|c|c|}
\hline $\begin{array}{c}\text { Pengaruh } \\
\text { Antar Variabel }\end{array}$ & Koefisien & $\begin{array}{c}\mathbf{t} \\
\text { Statistik }\end{array}$ & $\begin{array}{c}\mathbf{t} \\
\text { Tabel }\end{array}$ & $\begin{array}{c}P \\
\text { Value }\end{array}$ & Ket \\
\hline Iklim Organisasi -> OCB $(\mathrm{Z}$-> Y) & 0,298 & 2,362 & 1,960 & 0,019 & Sig \\
\hline $\begin{array}{l}\text { Kepemimpinan Transformasional -> Iklim Organisasi (X- } \\
\text { > Z) }\end{array}$ & 0,465 & 3,047 & 1,960 & 0,002 & Sig \\
\hline Kepemimpinan Transfrmasional -> OCB (X -> Y) & 0,472 & 4,448 & 1,960 & 0,000 & Sig \\
\hline KT -> IO -> OCB & \multicolumn{4}{|c|}{$\begin{array}{l}0,472+(0,465 \times 0,298)=0,611 \\
\text { Koefisien }=0,611 \\
\text { T statistik }=9,644 \\
\text { P Value }=0,000\end{array}$} & \\
\hline
\end{tabular}

Sumber : Data primer diolah, 2017

Berdasarkan tabel diatas dapat diketahui bahwa :

1. Kepemimpinan Transformasional memiliki pengaruh positif dan signifikan dilihat dari koefisien jalur sebesar 0,472 terhadap OCB dengan nilai Pvalue 0,000 .

2. Iklim Organisasi memiliki pengaruh positif dan signifikan dilihat dari koefisien jalur sebesar 0,298 terhadap OCB dengan nilai Pvalue 0,019.

3. Kepemimpinan Transformasional memiliki pengaruh positif dan signifikan dilihat dari koefisien jalur sebesar 0,465 terhadap Iklim Organisasi dengan nilai Pvalue 0,002.

4. Kepemimpinan Transformasional memiliki pengaruh positif dan signifikan dilihat dari koefisien jalur sebesar 0,611 terhadap OCB melalui Iklim Organisasi dengan nilai Pvalue 0,000.

\subsubsection{Predictive Relevance $\left(\mathrm{Q}^{2}\right)$}

Teknik ini dapat merepresentasi synthesis dari cross-validation dan fungsi fitting dengan prediksi dari observed variabel dan estimasi dari parameter konstruk. Nilai $Q^{2}>0$ menunjukkan bahwa model mempunyai predictive relevance, sedangkan nilai $Q^{2}<0$ menunjukkan bahwa model kurang memiliki predictive relevance. $Q^{2}$ dapat dihitung dengan rumus sebagai berikut :

$Q^{2}=1-\left(1-R_{1}^{2}\right)\left(1-R_{2}^{2}\right) \ldots .\left(1-R_{n}^{2}\right)$

Keterangan:

$Q^{2}=Q$ Square (predictive relevance)

$\mathrm{R}^{2}=$ Koefisien determinasi

$Q^{2}=1-(1-0,216)(1-0,443)$

$Q^{2}=1-0,784 \times 0,557$

$Q^{2}=0,563$

Berdasarkan perhitungan diatas maka didapatkan hasil sebesar 0,563. Hasil ini menunjukkan bahwa model memiliki nilai predictive-relevance karena nilai yang dihasilkan $>0$. 


\section{PEMBAHASAN}

\subsection{Pengaruh Kepemiminan Transformasional terhadap OCB}

Hasil penelitian menunjukan bahwa kepemimpinan transformasional kepala Dinas DUKCAPIL Kota Mataram berpengaruh terhadap OCB pegawai. Setiap peran pemimpin dalam organisasi mampu mempengaruhi setiap perilaku pegawai yang dapat meningkatkan OCB dilingkungan DUKCAPIL Kota Mataram. Oleh karena itu, semakin efektif peran pemimpin dalam hal memberikan pengaruh ideal, motivasi inspirasi, stimulasi intelektual dan pertimbangan individu dalam pelaksanaan gaya kepemimpinan transformasional, maka akan semakin tinggi tingkat perilaku ekstra peran (OCB) yang ada di lingkungan Organisasi seperti para pegawai akan meningkatkan sikap dan perilaku Altruism, Courtesy, Sportmanship dan Conscientiousness serta Civic virtue.

Kepemimpinan merupakan salah satu faktor penentu yang dapat memunculkan perilaku OCB pegawai. Kepemimpinan adalah kegiatan untuk mempengaruhi perilaku orang lain, atau seni mempengaruhi perilaku manusia baik perorangan maupun kelompok ke arah tercapainya suatu tujuan tertentu (Thoha, 2006). Sedangkan Organizational citizenship behavior (OCB) adalah perilaku yang bukan merupakan bagian dari tugas yang telah dipersyaratkan secara formal bagi seorang karyawan tetapi secara keseluruhan mendorong fungsi efektif organisasi (Robbins, 2003:21).

Pada penelitian Podsakoff et al., (1996 dalam Utomo, 2002) bahwa "perilaku kepemimpinan Transformasional mempengaruhi bawahan untuk menghasilkan kinerja melebihi apa yang seharusnya atau melebihi level minimum yang dipersyaratkan organisasi". Dalam pandangan yang sama, penelitian Di Poala (dalam Tschannen-Moran, 2003) "dengan latar belakang lingkungan pendidikan menunjukkan sebuah hubungan kuat antara gaya kepemimpinan pada lingkungan universitas dengan perilaku ekstra peran".

Hasil penelitian ini didukung oleh beberapa penelitian terdahulu yang sudah dilakukan oleh Maysari, et.al (2010), Sari, et.al (2013), Zulbaldi, et.al (2014), Rahmi (2014), Amelia (2014), Surayanatha, et.al (2014), Putra, et.al (2015), Adipura, et.al (2015), Gunawan (2016), dan Muflikhun (2016) mengatakan bahwa kepemimpinan transformasional berpengaruh signifikan terhadap organizational citizenship behavior (OCB).

\subsection{Pengaruh Iklim Organisasi terhadap OCB}

Hasil penelitian menunjukkan bahwa iklim organisasi memiliki pengaruh positif dan signifikan terhadap Organizational Citizenship Behavior (OCB) sehingga dapat disimpulkan bahwa hipotesis kedua dapat diterima. Hasil penelitian ini didukung oleh penelitian yang dilakukan oleh Lubis, (2015), Utami, (2013), Waspodo, et.al (2013), Prihatsanti, et.al (201), dan Amelia (2014) mengatakan bahwa iklim organisasi berpengaruh terhadap organizational citizenship behavior (OCB).

Iklim organisasi dapat menjadi penyebab kualitas berkembangnya $O C B$ dalam suau organisasi. Menurut Organ (2006) terdapat bukti kuat yang mengemukakan bahwa iklim organisasi merupakan suatu kondisi awal yang utama yang memicu munculnya perilaku OCB. Di dalam iklim organisasi yang positif, karyawan merasa lebih ingin melakukan pekerjaannya melebihi apa yang telah disyaratkan dalam uraian pekerjaan, dan akan selalu mendukung tujuan organisasi jika mereka diperlakukan oleh para atasan dengan sportif dan dengan penuh kesadaran sera percaya bahwa mereka diperlakukan secara adil oleh organisasinya (Sloat, 1999). Konovsky dan Pugh (dalam Novliadi, 2007) menggunakan teori pertukaran sosial (social exchange theory) untuk berpendapat bahwa ketika karyawan telah puas terhadap pekerjaannya, mereka akan membalasnya. Pembalasan dari karyawan 
tersebut termasuk perasaan memiliki (sense of belonging) yang kuat terhadap organisasi dan perilaku seperti organizational citizhenship.

\subsection{Pengaruh Kepemimpinan Transformasional terhadap Iklim Organisasi}

Hasil analisis menunjukkan bahwa kepemimpinan transformasional memiliki pengaruh positif dan signifikan terhadap iklim organisasi. Peran kepemimpinan transformasional dalam mengubah persepsi, sikap dan perilaku pegawai DUKCAPIL Kota Mataram dapat mempengaruhi sifat lingkungan kerja yang dirasakan oleh para pegawai terhadap pekerjaannya. Dari kedua variabel ini dapat dilihat adanya kaitan antara gaya kepemimpinan transformasional yang diterapkan oleh kepala dinas DUKCAPIL dengan iklim organisasi yang tercipta dalam lingkungan DUKCAPIL Kota Mataram. Hal ini terlihat bahwa pimpinan menciptakan suasana di dalam lingkungan organisasi DUKCAPIL dengan mengarahakan dan mendukung para pegawainya yang saling menolong secara spontan bila bantuan diperlukan, pimpinan juga pada pengambil keputusan dalam organisasi selalu mengikutsertakan pegawainya yang ada dilingkungan DUKCAPIL, serta memberikan pujian selalu kepada pegawai yang sudah sesuai dengan tugas, tanggung jawab, kualifikasi. Jadi dalam hal ini terlihat adanya pengaruh dari gaya kepemimpinan transformasional terhadap iklim organisasi. Dimana membuktikan terciptanya iklim organisasi yang baik dan kondusif tidak terlepas dari gaya kepemimpinan yang ada yang sudah diterapkan pada organisasi tersebut.

Beberapa hasil penelitian menunjukkankan bahwa kepemimpinan transformasional berpengaruh terhadap iklim organisasi, diantaranya Amelia (2014) dan Pratama (2016). Sedangkan penelitian Crosley, (2014) dan Dele, Nanle, \& Abimbola, (2015) mengatakan bahwa kepemimpinan berpengaruh signifikan terhadap iklim organisasi.

Menurut Umam, (2010 : 270), Kepemimpinan dapat diartikan sebagai proses memengaruhi pikiran, perasaan, tingkah laku dan mengarahkan semua fasilitas untuk mendapat tujuan yang telah ditetapkan bersama. Sedangkan Stringer (2002) menyatakan bahwa iklim organisasi sebagai sesuatu yang dapat diukur pada lingkungan kerja baik secara langsung maupun tidak langsung berpengaruh pada pegawai dan pekerjaannya. Oleh sebab itu, dapat disimpulkan bahwa terdapat pengaruh antara kepemimpinan transformasional dengan iklim organisasi. Hal ini di dukung oleh pendapat Stringer (2002) mengemukakan bahwa terdapat lima faktor yang mempengaruhi terjadinya iklim organisasi, yaitu Lingkungan eksternal, strategi, praktik kepemimpinan, pengaturan organisasi, dan sejarah organisasi. Selain itu menurut Gibson, (2008:123-124) bahwa yang tergolong dalam faktor organisasi terdiri dari kepemimpinan, kompensasi, konflik, kekuasaan, struktur organnisasi, desain pekerjaan, budaya organisasi, iklim organisasi, desain organisasi, dan karir. Masing-masing faktor ini sangat menentukan, oleh karena itu orang yang ingin mengubah iklim suatu organisasi harus mengevaluasi masing-masing faktor tersebut.

\subsection{Pengaruh Kepemimpinan Transformasional terhadap OCB melalui Iklim Organisasi}

Hasil analisis membuktikan bahwa kepemimpinan Transformasional berpengaruh positif dan signifikan terhadap OCB melalui Iklim Organisasi. Hal ini dibuktikan dengan adanya suasana iklim organisasi yang selalu mendukung pegawai sehingga para pegawai merasakan bahwa iklim organisasi di lingkungan DUKCAPIL Kota Mataram sangat menyenangkan. Menurut Castro, et al., (2004 dalam Ngadiman, 2013), jenis perilaku anggota organisasi yang ditujukan untuk meningkatkan efektivitas organisasi, tanpa 
mengabaikan produktivitas, tujuan individu masing-masing karyawan yaitu disebut OCB. Dipola, et al., (2007 dalam Waspodo, 2012), menjelaskan bahwa OCB adalah perilaku karyawan yang mempraktikkan peranan tambahan dan menunjukkan sumbangannya kepada organisasi melebihi peran spesifikasinya dalam kerja.

Dari hasil penelitian dan beberapa pendapat diatas dapat dipertegas oleh hasil penelitian diantaranya Maysari, et.al (2010), Sari, et.al (2013), Zulbaldi, et.al (2014), Rahmi (2014), Amelia (2014), Surayanatha, et.al (2014), Putra, et.al (2015), Adipura, et.al (2015), Gunawan (2016), dan Muflikhun (2016), Pratama (2016). Sedangkan penelitian Crosley, (2014) dan Dele, Nanle, \& Abimbola, (2015), Lubis, (2015), Utami, (2013), Waspodo, et.al (2013), dan Prihatsanti, et.al (201), membuktikan bahwa kepemimpinan transformasional dan iklim organisasi berpengaruh terhadap organizational citizenship behavior (OCB).

\subsection{Kesimpulan}

\section{KESIMPULAN DAN SARAN}

Berdasarkan hasil analisis dan pembahasan dalam penelitian ini maka dapat ditarik kesimpulan bahwa :

1. Kepemimpinan Transformasional berpengaruh positif dan signifikan terhadap OCB. Semakin efektif kepemimpinan transformasional maka semakin tinggi perilaku ekstra peran atau OCB pada Kantor DUKCAPIL Kota Mataram.

2. Iklim Organisasi berpengaruh positif dan signifikan terhadap OCB. Semakin mendukung iklim organisasi maka akan tinggi perilaku ekstra peran atau OCB pada Kantor DUKCAPIL Kota Mataram.

3. Kepemimpinan Transformasional berpengaruh positif dan signifikan terhadap Iklim Organisasi. Semakin efektif kepemimpinan transformasional maka semakin mendukung iklim organisasi yang ada pada pada Kantor DUKCAPIL Kota Mataram.

4. Kepemimpinan Transformasional berpengaruh positif dan signifikan terhadap OCB melalui Iklim Organisasi. Semakin efektif kepemimpinan transformasional maka akan semakin tinggi perilaku ekstra peran atau OCB dilingkungan DUKCAPIL Kota Mataram.

\subsection{Saran}

Adapun beberapa saran dapat direkomendasikan yang dapat memberikan kontribusi bagi pegawai dan pengambil kebijakan di Lingkungan DUKCAPIL Kota Mataram dalam meningkatkan OCB di lingkungan organisasi:

1. Kepemimpinan Transformasional pada Lingkungan DUKCAPIL Kota Mataram dipersepsikan oleh responden merupakan terapan gaya kepemimpinan yang tergolong efektif, dimana mampu menyampaikan visi dan misi organisasi secara jelas kepada para pegawai, mampu merangsang kreativitas cara kerja pada pegawainya dan mampu memberikan inovasi terhadap pekerjaan, mengarahkan pegawainya untuk memecahkan masalah secara cermat dan selalu melatih dan memberi pengarahan kepada karyawannya. Jadi dalam hal ini perlu diperthankan indikator gaya kepemimpinan transformasional yang dinilai sangat efektif oleh responden.

2. Iklim organisasi pada Lingkungan DUKCAPIL Kota Mataram dipersepsikan sebagian besar responden memberikan nilai dengan kategori mendukung. Hal yang perlu dipertahankan yaitu pemeliharaan norma-norma dan kebijakan organisasi adalah kriteria keberhasilan dalam organiasi. Dalam hal ini, sebaiknya dapat lebih 
meningkatkan lagi iklim organisasi yaitu dengan memerhatikan aspek-aspeknya, seperti Hubungan antar personal, Manajemen partisipatif, Formalisasi dan standarisasi, Pelatihan dan pengembangan, Reward serta Obyektivitas dan rasionalitas. Hasil penelitian mengenai iklim organisasi ini secara umum sudah menunjukan kondisi yang sangat baik, namun, secara khusus perlu adanya peningkatan atau pengembangan yang lebih baik lagi dalam beberapa hal yaitu lebih meningkatkan dukungan dan penghargaan, menyempurnakan kebijakan serta komunikasi yang menjangkau seluruh pegawai.

3. Berdasarkan hasil penelitian mengenai Organization Citizenship Behavior (OCB) di Lingkungan DUKCAPIL Kota Mataram dengan menggunakan 5 indikator yaitu : alturism, civic virtue, conscentiousness, courtesy, sportsmanship, secara keseluruhan termasuk dalam kategori tinggi. Diharapkan bagi pegawai dapat mempertahankan hal ini untuk kemajuan dalam mencapai tujuan bersama di lingkungan DUKCAPIL Kota Mataram.

4. Keterbatasan Penelitian : pada penelitian ini tidak dapat menjangkau seluruh populasi yang ada, serta tidak menganalisa semua faktor yang mempengaruhi OCB.

5. Bagi peneliti berikutnya : sebaiknya memperhatikan hal-hal seperti subjek penelitian juga perlu diperluas dengan jumlah responden lebih besar sehingga ketepatan model dengan variasi pengaruhnya bisa lebih tinggi lagi dalam menemukan model yang optimal pada variabel yang diteliti serta menambah jumlah variabel indipenden agar lebih kompleks pengaruh terhadap OCB, seperti adanya variabel gaya kepemimpinan transaksional, dimana gaya kepemimpinan transaksional digunakan untuk membangkitkan semangat orang-orang yang terlibat dalam pengelolaan organisasi.

\section{DAFTAR PUSTAKA}

Adipurwa, A. G., \& Riana, I. G. (2015). Pengaruh Persepsi Kepemimpinan Transformasional terhadap Kepuasan Kerja dan Organizational Citizenship Behavior Guru SMA Negeri 3 Denpasar. E-Jural Manajemen Unud, 693-714.

Arifiani, R. S., Astuti, E. S., \& Ruhana, I. (2016). Pengaruh Kepemimpinan Transformasional terhadap Organizational Citizenship Behavior dan Kepuasan Kerja (Studi pada tenaga perawat RSUD. Dr. Saiful Anwar Malang. Jurnal Administrasi Bisnis, 127-135.

Crosley, V., 2014, Empirical Study on the Relationship between Ethical Leadership and Organizational Climate of Innovation, international journal. 3 (1) :1-166

Dele, A.O., Nanle, M., \& Abimbola, O.S., (2015), Impact of Leadership Style on Organizational Climate in the.

Gunawan, R. (2016). Pengaruh Kepemimpinan Transformasional terhadap Organizational Citizenship Behavior (OCB) pada PT Marchinery Tradeco cabang Surabaya. AGORA, 60-66.

Ghozali, I., dan Latan, H., 2015. Partial Least Squares, Konsep, Teknik dan aplikasi Menggunakan Program SmartPLS 3.0. Untuk Penelitian Empiris. Undip.

Lako, Anderas, 2004. Kepemimpinan dan Kinerja Organisasi Isu Teori dan Solusi. Yogyakarta: Amara Books.

Lubis, M. S. (2015). Pengaruh Iklim Organisasi dan Komitmen Organisasi terhadap pembentukan Organizational Citizenship Behavior (OCB) Karyawan dalam rangka Peningkatan Kinerja. E-Jurnal Apresiasi Ekonomi, 75-84. 
Muflikhun, S., (2016), Pengaruh Kepemimpinan Transformasional pada Organizational Citizenship Behavior (OCB) dengan Budaya Organisasi sebagai Variabel Mediasi (Studi pada PT. Pamor Spinning Mills Karanganyar Jawa Tengah). Tesis Manajemen Universitas Sebelas Maret Surakarta.

Ngadiman, Eliyana, A., \& Ratmawati, D. (2013). Influence Of Transformational Leadership And Organization Climate To The Work Satisfaction, Organizational Commitment And Organizational Citizenship Behavior On The Educational Personnel Of Sebelas Maret University, Surakarta. Educational Research International, 41-66.

Novliadi, P. 2007. Intensi Turnover Karyawan Ditinjau dari Budaya Perusahaan dan Kepuasan Kerja. Makalah : Fakultas Kedokteran, Jurusan Psikologi USU.

Podsakoff, P.M., MacKenzie. S.B., Paine, J.B., \& Bachrach, D.G. 2000. Organizational citizenship behaviors: A critical review of the theoretical and empirical literature and suggestions for future research. Journal of Management, 26, 513-563.

Purpa, T. S., \& Sudharma, I. N. (2015). Pengaruh Kepemimpinan Transformasional, Kepuasan Kerja, dan Komitment Organisasional terhadap Organizational Citizenship Behavior pada Warung Mina Peguyangan. E-Jurnal Udayana, 660-661.

Prihatsanti, U., \& Dewi, K. S. (2010). Hubungan Antara Iklim Organisasi dan Organizational Citizenship Behavior (OCB) pada Guru SD Negeri di Kecamatan Mojolaban Sukoharjo. Jurnal Psikologi Undip, 11-17.

Putra, I. N., \& Supartha, I. W. (2016). Pengaruh Kepemimpinan Transformasional terhadap Kepuasan Kerja dan OCB pada Serene Villas. E-Jurnal Manajemen Unud, 1717-1744.

Rahmi, B. M. (2014). Pengaruh Kepemimpinan Transformasional terhadap Organizational Citizenship Behavior dan Komitmen Organisasi dengan mediasi Kepuasan Kerja. 331-350.

Robbins, S.P, 2003. Perilaku Organisasi, Jilid 2, PT. Indeks Kelompok Gramedia, Jakarta.

Robbins, Stephen P. \& Timothy A. Judge. 2009. Organizational Behavior. 13 Three Edition, USA: Pearson International Edition, Prentice -Hall.

Sugiyono, (2008). Metode Penelitian Kunatitatif Kualitatif dan R\&D. Bandung Alfabeta.

Sari, N. I., \& Puspitadewi, N. W. (2013). Hubungan Antara Kepemimpinan Transformasional dengan Organizational Citizenship Behavior. Jurnal Penelitian, 1-7.

Suryanatha, A. N., \& Ardana, K. (2014). Pengaruh Kepemimpinan Transformasional dan Komitmen Organisasi terhadap Kepuasan Kerja Karyawan dan Organizational Citizenship Behavior (OCB) pada baleka Resort Hotel \& Spa Legian. Jurnal Manajemen Universitas Udayana, 1155-1170.

Sloat, K.C.M., 1999. Organizational Citizenship: Does Your Firm Inspire to be "Good Citizenship?" Profesional Safety, 44 : 20-23.

Titisari, Purnamie. 2014. Peranan Organizational Citizenship Behavior (OCB) Dalam Meningkatkan Kinerja Karyawan. Jakarta: Mitra Wacana Media.

Thoha Miftah. 2006. Kepemimpinan dalam Manajemen. PT. RajaGrafindo Persada : Jakarta

Tschannen-Moran, M. 2003. Fostering Organizational Citizenship in Schools: Transformational Leadership and Trust. Journal of Educational Administration. Chapter 6. pp. 1-36.

Waspodo, A.A., dan Minadaniati, L., 2012, Pengaruh Kepuasan Kerja dan Iklim terhadap Organizational Citizenship Behavior (OCB) karyawan pada PT. Trubus Swadaya Depok, Jurnal Riset Manajemen Sains Indonesia (JRMSI), Vol.3, No. 1.

Vannecia Marchelle Soegandhi, 2013, Pengaruh Kepuasan Kerja dan Loyalitas Kerja terhadap Organizational Citizenship Behavior pada Karyawan PT. Surya Timur Sakti Jatim, Jurnal AGORA Vol. 1, No. 1, 2013. 